\section{India: shed the bad science image}

Contrary to Mathai Joseph and Andrew Robinson's implication, there are many joys associated with doing science in India (Nature 508, 36-38; 2014).

For example, as a theoretical physicist, I am free to pursue curiosity-driven science, I spend little time writing grant proposals and I do not have to raise money to fund my group members. This fills my foreign colleagues with envy. I suspect that these colleagues, many of whom have made productive scientific visits to India, would rank Indian science well above 166 th in the world on a different scale of research quality.

I also disagree that we need "non-resident Indians" to partially staff an "empowered funding agency": India already has one of the world's largest scientific workforces. To me, this proposal smacks of colonialism, albeit in a new form, perhaps inspired by department closures and tenure abolitions in many Western universities.

Finally, I dislike your portrayal of the Taj Mahal wrapped in red tape to convey the call to 'Free Indian science.' Thirty years ago a Nature cover also featured a Taj Mahal postcard image. That seemed inappropriate to me, even as an undergraduate, for a serious discussion of science in India (see Nature 308, 581-600; 1984). I am now a professor and Indian science has arrived, along with an era of cultural sensitivity - but the iconography remains unchanged.

Shobhana Narasimhan Jawaharlal Nehru Centre for Advanced Scientific Research, Bangalore, India. shobhana@jncasr.ac.in

\section{India: research split harmed universities}

One factor that Mathai Joseph and Andrew Robinson do not consider in their discussion on Indian science is the disastrous effect of uncoupling education and research in the country's universities (see Nature 508, 36-38; 2014).

Several research institutes were created throughout India after it gained independence. These took away good students from the universities and made funding harder to come by, causing a decline in research. In turn, this diminished the number of science faculty members in universities and marred the spirit of education.

This is the opposite result to that predicted by the celebrated Indian spectroscopist Chandrasekhara Venkata Raman. He declared in the 1950s that the institutes would become "mausoleums of science". He strongly believed that the best research could only be done by the universities (see P. Balaram Curr. Sci. 75, 977; 1998).

Biswa Prasun Chatterji St Xavier's College, Mumbai, India. biswaprasun@gmail.com

\section{India: overhaul university teaching}

We believe that the quality of education in India is another factor that has been hampering scientific progress in the country since independence (see M. Joseph and A. Robinson Nature 508, 36-38; 2014).

Hundreds of thousands of students graduate from Indian universities each year. However, our own experience in selecting students indicates that many are ignorant of the basics, with underdeveloped reasoning skills and an inability to apply the knowledge they have.

The inadequacy of teaching methods could explain why none of India's universities is among the world's top 200. Learning needs to be more enquiry-based and tutorials more demanding; syllabuses should be overhauled, upgraded and modernized; and, to improve accountability, student-feedback mechanisms must become more effective.

It is also important to emphasize the value of highquality teaching skills when recruiting new faculty members, so that the students' technical and reasoning abilities can be fully developed.

Unless India reinvigorates its universities by reforming the teaching-learning process, it will keep failing to generate the workforce necessary to propel Indian science forwards. Dhruba J. Saikia Cotton College State University, Assam, India. vc@ccsu.ac.in

Rowena Robinson Indian Institute of Technology, Guwahati, India.

\section{Aim for balance in Ukraine reports}

Your assessment of the scientific implications of tensions arising between Russia and the United States over the Ukraine situation seems to reflect a Western political bias. This could weaken the very research collaborations you seek to encourage (see Nature 508, 149-150 and 162; 2014).

The language you use to describe the Russian regime for example, "Moscow's violation of international law cannot be tolerated" and "Western observers are stunned by Putin's resolute pursuit of power" would come as no surprise from, say, US or European media with a clear political leaning. It seems inappropriate from an 'international journal of science'.

A genuinely international perspective would not overlook the wider political narrative of countries such as China, India and Brazil, who did not join the immediate condemnation of Russia.

Scientific advances in international research environments generally flourish despite cultural and political differences. They may not be so resilient if suspicion and hostility are aroused.

\author{
Andrew Isaac Meso CNRS \\ and Aix-Marseille University, \\ Marseille, France. \\ andrew.meso@univ-amu.fr
}

\section{Help poster sessions to grab attention}

Research findings at conferences are now more often conveyed using posters than by oral presentation. Yet the development of posters as a medium has not kept pace with the steady increase in their popularity.

Posters were first used to convey scientific results 45 years ago at the 6 th meeting of the Federation of European Biochemical Societies. Sessions were similar to today's, but were shorter and had only about 15 displays per session, so audience engagement was easier.

The worldwide increase in poster presentation as a communication medium should benefit authors and users. Instead, poster authors complain of limited exposure for their work, resulting in a lack of kudos and restricted networking opportunities with other conference participants.

Improving audience circulation, organizing sessions better and providing clear presentation guidelines would help the results on display to capture and hold attention. Nicholas Rowe University of Lapland, Rovaniemi, Finland. nrowe@ulapland.fi

\section{CORRECTION}

The Outlook article

'Neuroscience: Hardwired for taste' (Nature 486, S7-S9;

2012) incorrectly stated that $L$ cells manufacture a glucose transporter: it is the absorptive intestinal cells that make this. Also, the article overlooked the contribution of the ShiraziBeechey lab at the University of Liverpool in confirming sweet and umami receptors in the gut. 